\title{
Article \\ Power Flows and Losses Calculation in Radial Networks by Representing the Network Topology in the Hierarchical Structure Form
}

\author{
Aminjon Gulakhmadov $1,2,3,4{ }^{(\mathbb{D}}$, Salima Asanova ${ }^{5}\left(\mathbb{D}\right.$, Damira Asanova ${ }^{5}$, Murodbek Safaraliev ${ }^{6, *(\mathbb{D})}$, \\ Alexander Tavlintsev ${ }^{6}\left(\mathbb{D}\right.$, Egor Lyukhanov ${ }^{6}\left(\mathbb{D}\right.$, Sergey Semenenko ${ }^{6}\left(\mathbb{D}\right.$ and Ismoil Odinaev ${ }^{6}(\mathbb{C})$ \\ 1 Research Center for Ecology and Environment of Central Asia, Xinjiang Institute of Ecology and Geography, \\ Chinese Academy of Sciences, Urumqi 830011, China; aminjon@ms.xib.ac.cn \\ 2 State Key Laboratory of Desert and Oasis Ecology, Xinjiang Institute of Ecology and Geography, \\ Chinese Academy of Sciences, Urumqi 830011, China \\ 3 Ministry of Energy and Water Resources of the Republic of Tajikistan, Dushanbe 734064, Tajikistan \\ 4 Institute of Water Problems, Hydropower and Ecology of the National Academy of Sciences of Tajikistan, \\ Dushanbe 734002, Tajikistan \\ 5 Faculty of Energy, Kyrgyz State Technical University Named After I. Razzakov, Bishkek 720044, Kyrgyzstan; \\ a_sm07@mail.ru (S.A.); damira.asanova@mail.ru (D.A.) \\ 6 Department of Automated Electrical Systems, Ural Federal University, 620002 Yekaterinburg, Russia; \\ a.s.tavlintsev@urfu.ru (A.T.); ealuhanov@yandex.ru (E.L.); sergey.semenenko@urfu.ru (S.S.); \\ ismoil.odinaev@urfu.ru (I.O.) \\ * Correspondence: murodbek_03@mail.ru
}

Citation: Gulakhmadov, A.; Asanova,

S; Asanova, D.; Safaraliev, M.;

Tavlintsev, A.; Lyukhanov, E.;

Semenenko, S.; Safaraliev, M. Power Flows and Losses Calculation in Radial Networks by Representing the Network Topology in the Hierarchical Structure Form. Energies 2022, 15, 765. https://doi.org/ 10.3390/en15030765

Academic Editors: Alberto Cavallo and Javier Contreras

Received: 11 December 2021

Accepted: 15 January 2022

Published: 21 January 2022

Publisher's Note: MDPI stays neutral with regard to jurisdictional claims in published maps and institutional affiliations.

Copyright: (C) 2022 by the authors. Licensee MDPI, Basel, Switzerland. This article is an open access article distributed under the terms and conditions of the Creative Commons Attribution (CC BY) license (https:// creativecommons.org/licenses/by/ $4.0 /)$.

\begin{abstract}
This paper proposes a structured hierarchical-multilevel approach to calculating the power flows and losses of electricity in radial electrical networks with different nominal voltages at given loads and voltages of the power source. The researched electrical networks are characterized by high dimensionality, dynamism of development, but also insufficient completeness and reliability of state information. The approach is based on the representation of the initial network graph in the form of a hierarchical-multilevel structure, divided into two stages with rated voltages $U_{n o m} \leq 35 \mathrm{kV}$ and $U_{n o m} \geq 35 \mathrm{kV}$, and using the traditional (manual) engineering two-stage method, where the calculation is performed in a sequence from bottom to top (stage 1) and from top to bottom (stage 2), moving along the structure of the network. The application of the above approach makes it possible to obtain an algorithm for implementation on a computer, which is characterized by universality (for an arbitrary configuration and complexity of the network), high performance and low requirements for the computer memory.
\end{abstract}

Keywords: distribution electric networks; electricity losses; transformer; structured hierarchicalmultilevel approach; load; directed graph; algorithm

\section{Introduction}

It is well known that electricity losses in electrical grids of power systems consist of the following components:

- Technological factor-it directly depends on the characteristic physical processes, and can change under the influence of the load component, conditionally fixed costs, as well as climatic conditions;

- $\quad$ Energy costs spent on the operation of auxiliary equipment and ensuring the necessary conditions for the work of technical personnel;

- Commercial losses - this category includes errors in metering devices, as well as other factors that cause the underestimation of electric energy.

When determining electrical energy losses in electrical networks of power systems, the greatest interest, from the point of view of the specific contribution to the total amount 
of losses, structural complexity and complexity of the calculation, are the load losses in the lines and power transformers of the network [1-6].

A significant part of electricity is transmitted through highly branched distribution networks of $6-20 \mathrm{kV}$, which mainly operate as a radial network. These networks are characterized by high dimension, dynamism of development, insufficient completeness and reliability of state information [7-9]. The magnitude of losses in these networks can reach up to $70 \%$ of the total electrical energy losses; therefore, an objective estimation of electricity losses in the considered electrical networks is extremely important.

The features of the calculating electricity losses tasks in radial electric networks with nominal voltage $U_{n o m} \geq 35 \mathrm{kV}$ include: considering the reactive power $Q_{C}$ of the power lines; considering corona losses $\Delta P_{\text {cor }}$ in overhead lines; considering power losses $\Delta \underline{S}$ in network elements; considering the longitudinal $\Delta U$ and transverse $\delta U$ components of the voltage drop in the network elements, calculated according to the actual voltage $U$ of the network, and not according to the nominal $U_{\text {nom }}$ [10]. Distribution networks with $U_{\text {nom }} \geq 35 \mathrm{kV}$ are similar in configuration to networks of 6-20 kV; from the point of view of sate information, they are sufficiently provided and they are more adjacent to multi-circuit electrical networks [11]. These specific features of $U_{\text {nom }} \geq 35 \mathrm{kV}$ networks indicate that, in order to determine electricity losses, it is necessary to calculate power flows, i.e., determine the unknown voltages in nodes, flows and power losses in network elements (power lines and transformers) [12-19]. These power flow calculations [11,20,21] are performed, as a rule, at a given voltage of the power supply and constant values of the loads on the low-voltage side of step-down consumer substations (this is the way of specifying the initial information that most closely matches the operating conditions and is typical for the electrical networks under consideration).

To solve such problems, it is important to develop universal and efficient algorithmic methods from the point of view of implementation and computation complexity.

Therefore, in [2,6,22], a structured hierarchical-multilevel approach was applied when solving the following problems:

- Element-by-element calculation of load electricity losses in distribution electric networks 6-20 kV;

- Calculation of power flows and losses of electricity in radial electrical networks of $35 \mathrm{kV}$ and above, at given loads and voltage of the power source;

- Problems of designing a system for electrical distribution networks' overhead lines wire breakage remote diagnostics.

The use of this approach made it possible to obtain a universal (for an arbitrary configuration and network complexity) and efficient (in terms of the number of computational operations and the amount of computer memory consumed) algorithm.

In this paper, the described approach was used to calculate the power flows and losses of electricity in radial circuits with different nominal voltages at given loads and voltage of the power source. The advantage of this approach is that the use of the apparatus of computing Petri nets for its implementation makes it possible to build a self-organizing multicomponent computational algorithm, convenient from the point of view of implementation on a computer, modification and interpretation, as well as from the point of view of the organization of parallel-sequential computations in order to increase the computing speed.

A distribution network with $\mathrm{n}$ nodes and $\mathrm{m}$ network elements (power lines and transformers) with a tree structure is considered, which contains transformers connecting subnets with different nominal voltages. The specified parameters are: network scheme; loads powers; resistances and conductivities of elements; power source voltage and nominal sub-network voltages. The unknown parameters are: unknown voltages at nodes, flows and power losses at elements, power losses in the network as a whole. 


\section{Structural Network Model}

The scheme of a radial electric network with different nominal voltages is represented in the form of an oriented graph $(L, \Gamma)$ with a tree structure (see Figure 1 ), where $L$ is a set of network nodes (graph vertices); $\Gamma$ is a mapping of the set $L$ to $L$, showing how the nodes of the network from the set $L$ are connected to each other, meaning that:

$$
\begin{gathered}
\Gamma: L \rightarrow L, \quad \Gamma(i) \subset L, \quad \forall i \in L \backslash L_{0}, \\
\Gamma \subseteq L \times L, \quad \Gamma_{i}=\{i\} \times \Gamma(i), \quad \forall i \in L \backslash L_{0}, \\
\Gamma=\bigcup_{i \in L \backslash L_{0}} \Gamma_{i}, \quad L \backslash\{0\}=\bigcup_{i \in L \backslash L_{0}} \Gamma(i), \quad L_{0} \subset L, \\
\Gamma(i)=\varnothing, \quad \Gamma_{i}=\varnothing, \quad \forall i \in L_{0},
\end{gathered}
$$

where $L_{0}$ - the set of end vertices of the $(L, \Gamma)$ graph, i.e., end (load) network nodes; $L \backslash L_{0}-$ set of intermediate graph vertices $(L, \Gamma)$, including $i=0$ vertex, i.e., including power supply node; $\Gamma(i)$ — set of end vertices of edges, which source vertex is a vertex $i \in L \backslash L_{0}$; $\Gamma_{i}$-set of edges $(i, j)$, which source vertex is vertex $i \in L \backslash L_{0}$.

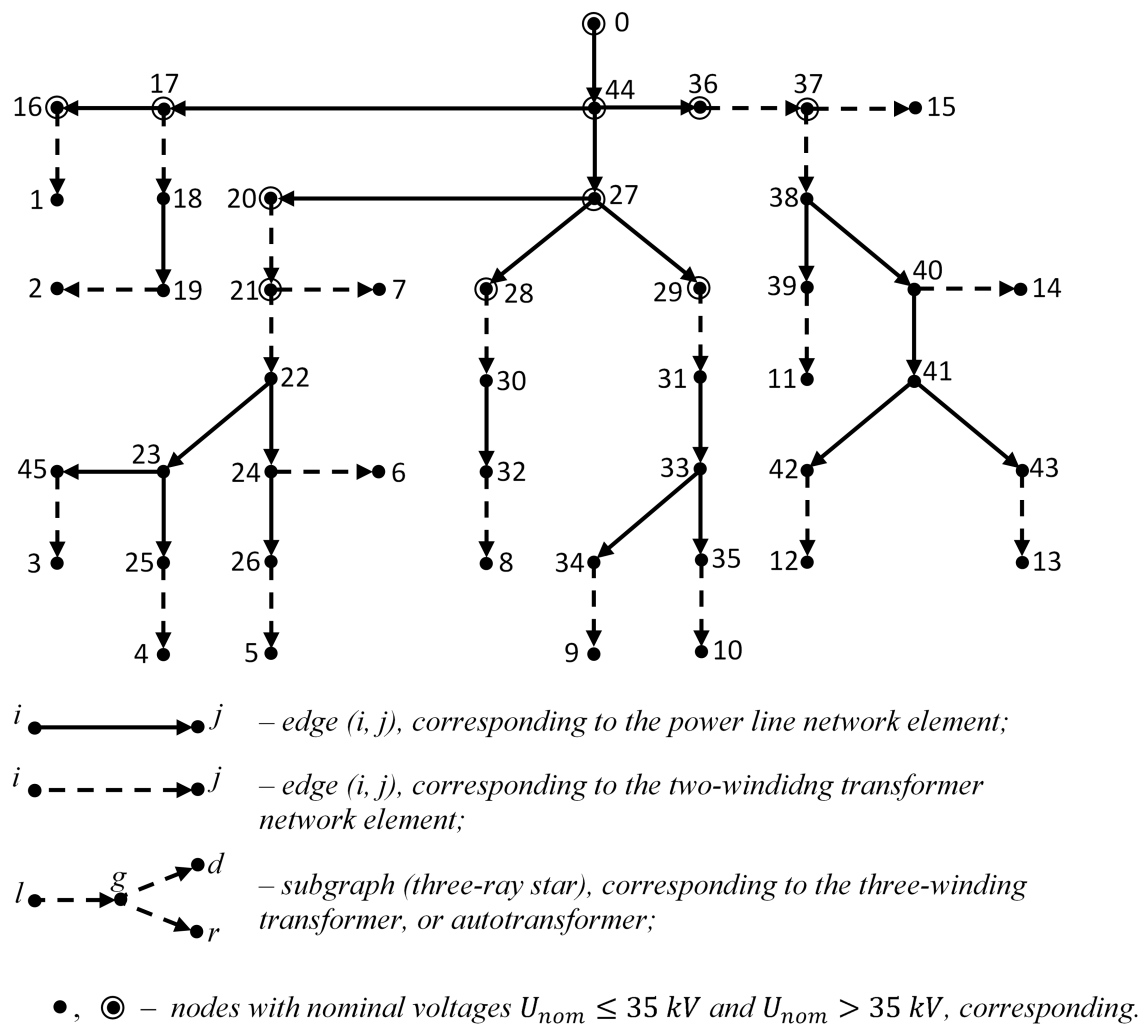

Figure 1. Graph of a radial electrical network with different rated voltages.

A set $L_{Y}$ is introduced, the elements of which are the numbers of subgraphs' internal nodes (three-ray stars) corresponding to three-winding transformers or autotransformers of the electrical network (here, an internal node is a node connecting all three rays of a subgraph).

Each vertex $i \in L$ of the graph $(L, \Gamma)$ of the network is associated with a nominal voltage $U_{n o m, i}$. The elements of the sets $L_{Y}$ and $\left\{U_{n o m, i} \mid i \in L\right\}$ serve as signs for the choice of the equivalent circuit and the corresponding calculation formula for each element $(i, j) \in \Gamma$ when calculating the power flows and losses of electricity in the network.

Figure 2 shows equivalent circuits of network elements with different nominal voltages $[11,21]$ : 
(a) Equivalent circuit of a two-winding transformer with $U_{n o m, i}>35 \mathrm{kV}$;

(b) Equivalent circuit of a power line with $U_{n o m, i}>35 \mathrm{kV}$;

(c) Equivalent circuit of a two-winding transformer with $U_{n o m, i} \leq 35 \mathrm{kV}$;

(d) Equivalent circuit of a power line with $U_{n o m, i} \leq 35 \mathrm{kV}$;

(e) Equivalent circuit of a three-winding transformer (three-ray star) or autotransformer, where $(l, g)$ corresponds the primary voltage winding; $(g, d),(g, r)$ - secondary voltage winding; $g$-inner node of a three-pointed star connecting the $(l, g),(g, d),(g, r)$.

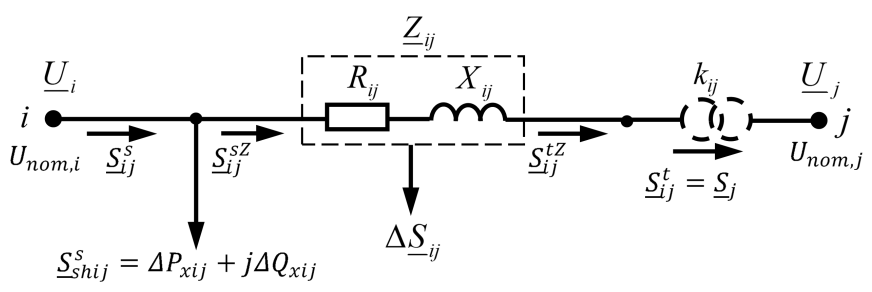

(a) Two-winding transformer with $U_{n o m, i}>35 \mathrm{kV}$

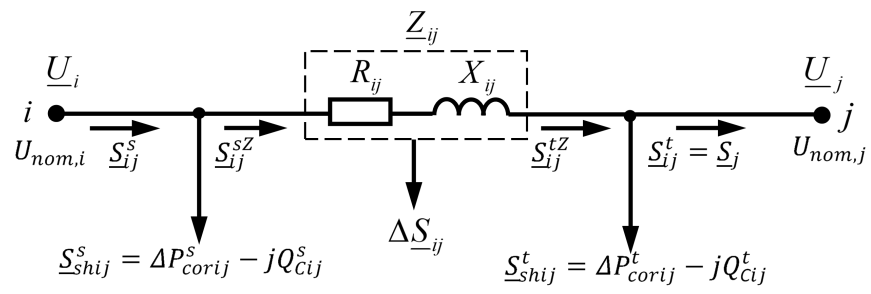

(b) Power line with $U_{n o m, i}>35 \mathrm{kV}$

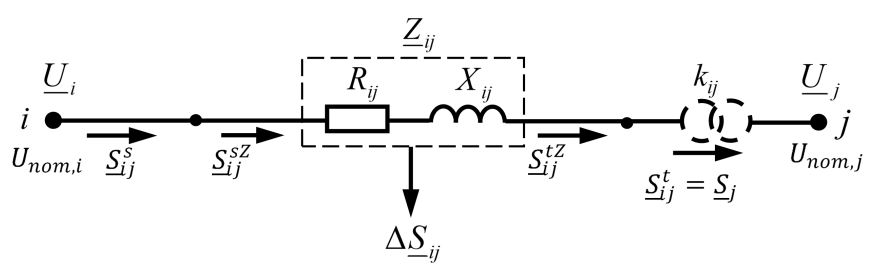

(c) Two-winding transformer with $U_{n o m, i} \leq 35 \mathrm{kV}$

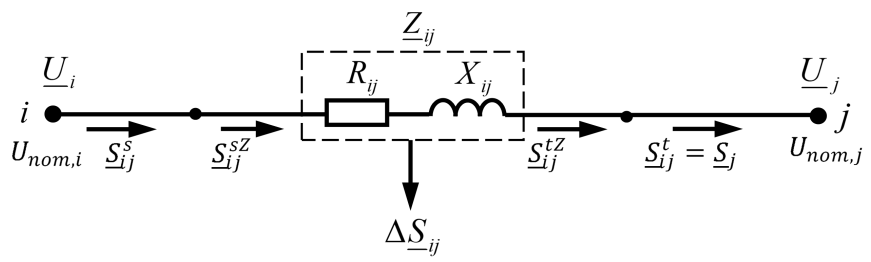

(d) Power line with $U_{n o m, i} \leq 35 \mathrm{kV}$

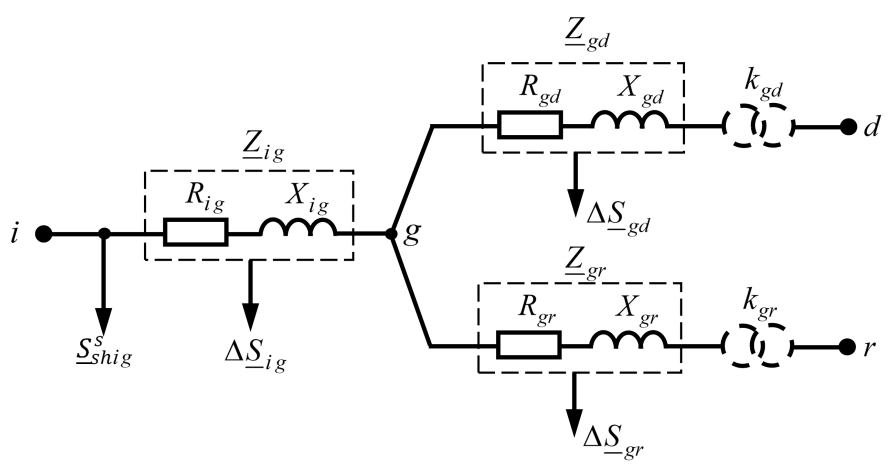

(e) Three-winding transformer (three-ray star) or autotransformer

Figure 2. Equivalent circuits of network elements with different nominal voltages. 
Note that the equivalent circuit of the edge $(l, g)$ is similar to the equivalent circuit of (a) without an ideal transformer, and the equivalent circuits of the edges $(g, d),(g, r)$ are identical with the equivalent circuit (c).

In Figure 2, the following designations are adopted: $\underline{S}_{i j}^{S}, \underline{S}_{i j}^{t}-$ power flows, respectively, at the beginning and at the end of the section (source and target, respectively) $(i, j) \in \Gamma$; $\underline{S}_{i j}^{s Z}, \underline{S}_{i j}^{t Z}$ - power flows, respectively, at the beginning and at the end of the resistance $\underline{Z}_{i j}$ of Section $(i, j) \in \Gamma ; \underline{S}_{j}$-power flowing through a node $j \in L$ (since the power flows are directed from the power supply node $i=0$ to the set of load nodes $L_{0}$, as can be seen in Figure 1), then, $\underline{S}_{i j}^{t}=\underline{S}_{j},(\forall(i, j) \in \Gamma) ; \underline{U}_{i}, \underline{U}_{j}$-node stresses, respectively, at the beginning and at the end of Section $(i, j) \in \Gamma ; \underline{S}_{s h i j}^{S}, \underline{S}_{s h i j}^{t}$-power flows (losses) in shunts, i.e., in transverse branches, respectively, at the beginning and at the end $\operatorname{Section}(i, j) \in \Gamma$; $\Delta \underline{S}_{i j}$-power loss in resistance $\underline{Z}_{i j} ; \Delta P_{x i j}$-active power losses in the steel of the transformer for magnetization reversal (hysteresis) and eddy currents; $\Delta Q_{x i j}$-losses of reactive power in the steel of the transformer for its magnetization; $\Delta P_{c o r i j}$-active corona power losses (or in isolation); $Q_{C i j}$-charging shunt power; $k_{i j}$-transformation ratio.

Furthermore, to calculate the above parameters of the power flow, the following parameters of the network elements are used: $R_{i j}, X_{i j}$-respectively, the active and reactive resistances of the longitudinal branch of Section $(i, j) \in \Gamma ; q_{i j}, b_{i j}$-respectively, the active and reactive conductivity in the transverse branches of Section $(i, j) \in \Gamma$.

The procedure for choosing an equivalent circuit and the corresponding calculation formula for each Section $(i, j) \in \Gamma$ when calculating the power flows and losses of electricity in the network is described using the predicate functions given in Table 1.

In Table 1: $F_{S}^{(p)}(\ldots)$-operators for calculating power flows $(S)$ of Section $(i, j)$, type $p$; and $F_{U}^{(p)}(\ldots)$-operators for calculating voltages $(U)$ in nodes at the ends of sections $(i, j)$, type $p$.

Table 1. Predicate functions for choosing the equivalent circuit and calculation formula for each Section $(i, j) \in \Gamma$ of the network.

\begin{tabular}{|c|c|c|c|}
\hline $\begin{array}{l}\text { Section Type } \\
\text { Number }(p)\end{array}$ & $\begin{array}{l}\text { Predicate Functions for Choosing the } \\
\text { Equivalent Circuit and Calculation } \\
\text { Formula for Each Section }(i, j) \in \Gamma\end{array}$ & $\begin{array}{c}\text { Equivalent Schemes: } \\
\text { Figure } 2\end{array}$ & $\begin{array}{l}\text { Operators for Calculating Power } \\
\text { Flows } F_{S}^{(.)}(\ldots) \text { and Voltages } F_{U}^{(.)}(\ldots) \\
\text { in the Network Nodes }\end{array}$ \\
\hline 1 & $\begin{array}{c}\left(j \notin L_{Y}\right) \wedge\left(U_{\text {nom.i }}>\right. \\
35 \mathrm{kV}) \wedge\left(U_{\text {nom }, i}>U_{\text {nom }, j}\right)\end{array}$ & (a) & $F_{S}^{(1)}(\ldots) F_{U}^{(1)}(\ldots)$ \\
\hline 2 & $\begin{array}{c}\left(j \notin L_{Y}\right) \wedge\left(U_{n o m, i}>\right. \\
35 \mathrm{kV}) \wedge\left(U_{n o m, i}=U_{n o m, j}\right)\end{array}$ & (b) & $F_{S}^{(2)}(\ldots) F_{U}^{(2)}(\ldots)$ \\
\hline 3 & $\begin{array}{c}\left(j \notin L_{Y}\right) \wedge\left(U_{n o m, i} \leq\right. \\
35 \mathrm{kV}) \wedge\left(U_{n o m, i}>U_{n o m, j}\right)\end{array}$ & (c) & $F_{S}^{(3)}(\ldots) F_{U}^{(1)}(\ldots)$ \\
\hline 4 & $\begin{array}{c}\left(j \notin L_{Y}\right) \wedge\left(U_{n o m, i} \leq\right. \\
35 \mathrm{kV}) \wedge\left(U_{n o m, i}=U_{n o m, j}\right)\end{array}$ & (d) & $F_{S}^{(4)}(\ldots) F_{U}^{(2)}(\ldots)$ \\
\hline 5 & $\begin{array}{c}\left(j \in L_{Y}\right) \wedge\left(U_{n o m, i}>\right. \\
35 \mathrm{kV}) \wedge\left(U_{n o m, i}=U_{n o m, j}\right)\end{array}$ & (e), where $i=l, j=q$ & $F_{S}^{(5)}(\ldots) F_{U}^{(2)}(\ldots)$ \\
\hline 6 & $\begin{array}{c}\left(i \in L_{Y}\right) \wedge\left(U_{\text {nom }, i}>\right. \\
35 \mathrm{kV}) \wedge\left(U_{\text {nom }, i}>U_{\text {nom }, j}\right)\end{array}$ & $\begin{array}{c}\text { (e), where } i=g, j=d \text { or } \\
r\end{array}$ & $F_{S}^{(3)}(\ldots) F_{U}^{(1)}(\ldots)$ \\
\hline
\end{tabular}

The following is an example of the formation of computational sets for the original network topology in Figure 1. For the directed network graph shown in Figure 1: $L=\{0,1,2, \ldots, 45\} ; L_{0}=\{1,2,3, \ldots, 15\} ; L \backslash L_{0}=\{0,16, \ldots, 44\} ;$ sets $\Gamma(i), \Gamma_{i}, \forall i \in L \backslash L_{0}$ from (1) to (4), corresponding to this example are given in Table 2; the edges set $\Gamma$ is obtained using Formula (3), i.e., the union of sets $\Gamma_{i}, \forall i \in L \backslash L_{0}$ (see Table 2). 
Table 2. Sets $\Gamma(i)$ and $\Gamma_{i}, \forall i \in L \backslash L_{0}$.

\begin{tabular}{|c|c|c|}
\hline & Sets $\Gamma(i) \forall i \in L . L_{0}$ & Sets $\Gamma_{i} \forall i \in L . L_{0}$ \\
\hline 1 & $\Gamma(0)=\{44\}$ & $\Gamma_{0}=\{(0,44)\}$ \\
\hline 2 & $\Gamma(16)=\{1\}$ & $\Gamma_{16}=\{(16,1)\}$ \\
\hline 3 & $\Gamma(17)=\{16,18\}$ & $\Gamma_{17}=\{(17,16),(17,18)\}$ \\
\hline 4 & $\Gamma(18)=\{19\}$ & $\Gamma_{18}=\{(18,19)\}$ \\
\hline 5 & $\Gamma(19)=\{2\}$ & $\Gamma_{19}=\{(19,2)\}$ \\
\hline 6 & $\Gamma(20)=\{21\}$ & $\Gamma_{20}=\{(20,21)\}$ \\
\hline 7 & $\Gamma(21)=\{7,22\}$ & $\Gamma_{21}=\{(21,7),(21,22)\}$ \\
\hline 8 & $\Gamma(22)=\{23,24\}$ & $\Gamma_{22}=\{(22,23),(22,24)\}$ \\
\hline 9 & $\Gamma(23)=\{25,45\}$ & $\Gamma_{23}=\{(23,25),(23,45)\}$ \\
\hline 10 & $\Gamma(24)=\{6,26\}$ & $\Gamma_{24}=\{(24,6),(24,26)\}$ \\
\hline 11 & $\Gamma(25)=\{4\}$ & $\Gamma_{25}=\{(25,4)\}$ \\
\hline 12 & $\Gamma(26)=\{5\}$ & $\Gamma_{26}=\{(26,5)\}$ \\
\hline 13 & $\Gamma(27)=\{20,28,29\}$ & $\Gamma_{27}=\{(27,20),(27,28),(27,29)\}$ \\
\hline 14 & $\Gamma(28)=\{30\}$ & $\Gamma_{28}=\{(28,30)\}$ \\
\hline 15 & $\Gamma(29)=\{31\}$ & $\Gamma_{29}=\{(29,31)\}$ \\
\hline 16 & $\Gamma(30)=\{32\}$ & $\Gamma_{30}=\{(30,32)\}$ \\
\hline 17 & $\Gamma(31)=\{33\}$ & $\Gamma_{31}=\{(31,33)\}$ \\
\hline 18 & $\Gamma(32)=\{8\}$ & $\Gamma_{32}=\{(32,8)\}$ \\
\hline 19 & $\Gamma(33)=\{34,35\}$ & $\Gamma_{33}=\{(33,34),(33,35)\}$ \\
\hline 20 & $\Gamma(34)=\{9\}$ & $\Gamma_{34}=\{(34,9)\}$ \\
\hline 21 & $\Gamma(35)=\{10\}$ & $\Gamma_{35}=\{(35,10)\}$ \\
\hline 22 & $\Gamma(36)=\{37\}$ & $\Gamma_{36}=\{(36,37)\}$ \\
\hline 23 & $\Gamma(37)=\{15,38\}$ & $\Gamma_{37}=\{(37,15),(37,38)\}$ \\
\hline 24 & $\Gamma(38)=\{39,40\}$ & $\Gamma_{38}=\{(38,39),(38,40)\}$ \\
\hline 25 & $\Gamma(39)=\{11\}$ & $\Gamma_{39}=\{(39,11)\}$ \\
\hline 26 & $\Gamma(40)=\{14,41\}$ & $\Gamma_{40}=\{(40,14),(40,41)\}$ \\
\hline 27 & $\Gamma(41)=\{42,43\}$ & $\Gamma_{41}=\{(41,42),(41,43)\}$ \\
\hline 28 & $\Gamma(42)=\{12\}$ & $\Gamma_{42}=\{(42,12)\}$ \\
\hline 29 & $\Gamma(43)=\{13\}$ & $\Gamma_{43}=\{(43,13)\}$ \\
\hline 30 & $\Gamma(44)=\{17,27,36\}$ & $\Gamma_{44}=\{(44,17),(44,27),(44,36)\}$ \\
\hline 31 & $\Gamma(45)=\{3\}$ & $\Gamma_{45}=\{(45,3)\}$ \\
\hline
\end{tabular}

In the considered graph of the electrical network, the following is shown:

- All end sections of the network are double-winding transformers, the end nodes of which form a set of load nodes $L_{0}$;

- $\quad$ at sections $(17,18),(28,30),(29,31)$, two-winding communication transformers are installed between network lines of different rated voltage;

- Two three-winding communication transformers are installed between the lines of the network of different rated voltages: the first corresponds to a three-ray star from three sections $(20,21),(21,7),(21,22)$ with an internal node $g=21$; the second-to a three-rayed star, consisting of three sections $(36,37),(37,15),(37,38)$ with an internal node $g=37$. Here, sections $(20,21),(36,37)$ correspond to the primary windings, and sections $(21,7),(21,22)$ and $(37,15),(37,38)$ - to the secondary windings of a three-winding coupling transformer;

- Communication transformers divide the initial network graph into two subgraphs: a subgraph with a lower step of the rated voltage $U_{n o m} \leq 35 \mathrm{kV}$, whose nodes are shown as a point "."; subgraph with the upper step of the rated voltage $U_{n o m}>35 \mathrm{kV}$, which nodes are shown as a point with a circle.

The set of internal nodes of three-winding coupling transformers has the form $L_{Y}=\{21,37\}$. 


\section{Calculation Algorithm Formulation and Discussion}

3.1. Description of a Structured Hierarchically Multilevel Approach to the Calculation of Power Flows and Losses of Electricity in Radial Networks with Different Rated Voltages

To calculate the power flows and losses of electricity in radial electrical networks with different rated voltages, a two-stage method is used: in the first stage (from bottom to top), the flows and power losses in lines and transformers (autotransformers) are determined from loads to the power source; at the second stage, in the reverse order (from bottom to top), the voltages $U_{i}$ for nodes $i \in L_{0}$ are calculated from the power supply to the loads.

Unlike [2,6,22], this work considers electrical networks with different nominal voltages, i.e., networks with two subnets: a subnetwork with nominal voltage $U_{\text {nom }} \leq 35 \mathrm{kV}$ and a subnetwork with $U_{\text {nom }}>35 \mathrm{kV}$. To calculate the power flow of subnet with $U_{n o m}>35 \mathrm{kV}$ a two-stage iterative method is used [11,21], where the "bottom-up" and "top-down" stages are repeated until the required calculation accuracy is obtained. To calculate the power flow of subnet with $U_{\text {nom }} \leq 35 \mathrm{kV}$-a two-stage method is used with one pass of the "bottom-up" and "top-down" stages.

To establish and organize such a sequence of calculations, the initial graph is represented in the form of a hierarchically multilevel structure.

Since the original network consists of two subnets with different nominal voltages$U_{\text {nom }} \leq 35 \mathrm{kV}$ and $U_{\text {nom }}>35 \mathrm{kV}$-the multilevel structure should be represented as two steps with different rated voltages: step I with $U_{\text {nom }} \leq 35 \mathrm{kV}$; and step II with $U_{\text {nom }}>35 \mathrm{kV}$ (for the considered example of the network, see Figure 3 ).

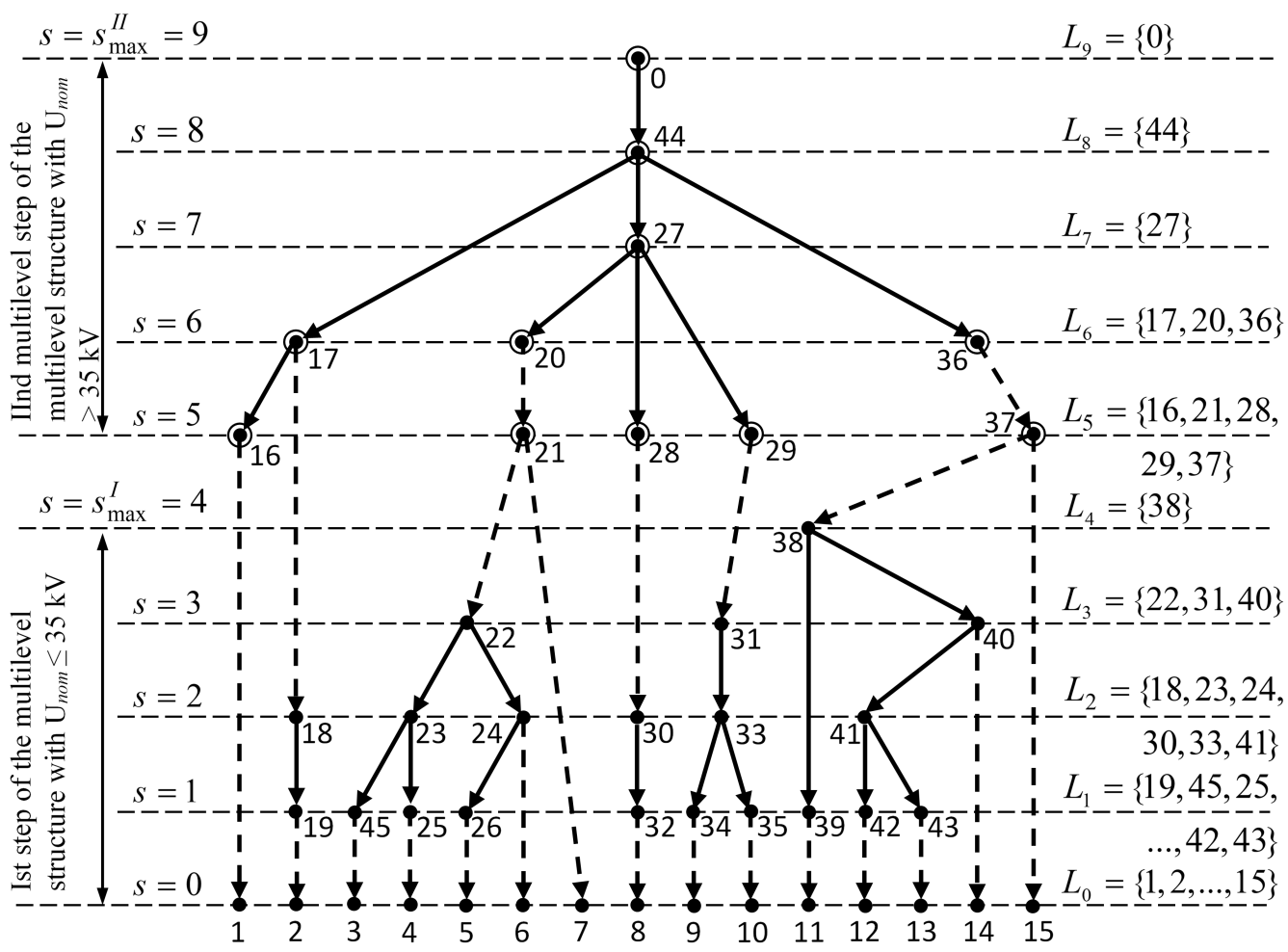

Figure 3. Hierarchical-multilevel structure of the initial network graph $(L, \Gamma)$ with two nominal voltage subnetworks.

The proposed approach consists of the following steps.

3.2. Representation of the Initial Network Graph in the Form of a Hierarchical Multilevel Structure with Two Steps of the Nominal Voltage

The example of the representation process result is presented on the Figure 3. 
Step 0. Calculate $s=0$ and form the set of vertices of the $s=0$-th level of the hierarchy from the terminal vertices of the initial network graph, i.e., $L_{0}$ set;

Step 1. Form the initial state of the sets $L_{s}^{H}, L_{s}^{L}$ (where $s=0$ ):

$$
L_{0}^{H}=L \backslash L_{0}, L_{0}^{L}=L_{0}
$$

Step 2. Set the initial value of the step number of the nominal voltage: $a=0$;

Step 3. Calculate the next step number: $a=a+1$;

Step 4. Calculate the number of the next top level in the hierarchy: $s=s+1$;

Step 5. If $a=1$, then form a set $L_{s}$ of informationally secured vertices of the $s$-th hierarchy level of the multilevel structure first step with $U_{\text {nom }} \leq 35 \mathrm{kV}$ :

$$
L_{s}=\left\{i \in L_{s-1}^{H} \mid\left(\Gamma(i) \subseteq L_{s-1}^{L}\right) \wedge\left(U_{n o m, i} \leq 35 \mathrm{kV}\right)\right\} .
$$

Step 6. If $a=2$, then form a set $L_{s}$ informationally secured vertices of the s-th hierarchy level of the second step of the multilevel structure with $U_{n o m}>35 \mathrm{kV}$ :

$$
L_{s}=\left\{i \in L_{s-1}^{H} \mid\left(\Gamma(i) \subseteq L_{s-1}^{L}\right) \wedge\left(U_{n o m, i}>35 \mathrm{kV}\right)\right\} .
$$

Step 7. If $L_{s} \neq \varnothing$, then calculate the new state of the sets $L_{s}^{H}, L_{s}^{L}$ :

$$
\begin{aligned}
& L_{s}^{H}=L_{s-1}^{H} \backslash L_{s}, \\
& L_{s}^{L}=L_{s-1}^{L} \cup L_{s},
\end{aligned}
$$

where $L_{s}^{H} \cup L_{s}^{L}=L, \forall s \in\{0,1,2, \ldots\}$.

Step 8. If $L_{s}=\varnothing$, then go to step 9 , otherwise go to step 4 .

Step 9. If $a=1$, then:

$$
s=s-1, \quad s_{\max }^{I}=s .
$$

Step 10. If $a=2$, then:

$$
s=s-1, \quad s_{\max }^{I I}=s .
$$

Step 11. If $L_{s}^{H} \neq \varnothing$ (or $L_{s}^{L} \neq L$ ), then go to step 3; otherwise, go to the block for calculating power flows and losses of electricity in the network, i.e., to step 12 . The results of this algorithm are:

- Set of level numbers $\left\{0,1,2, \ldots, s_{\max }^{I}\right\}$ of the first multilevel structure level with $U_{\text {nom }} \leq 35 \mathrm{kV}$;

- $\quad$ Set of level numbers $\left\{s_{\max }^{I}+1, s_{\max }^{I}+2, \ldots, s_{\max }^{I I}\right\}$ of the second multilevel structure level with $U_{\text {nom }}>35 \mathrm{kV}$;

- The set of network graph vertices for each s-th hierarchy level: $L_{s}, \forall s \in\left\{0,1,2, \ldots, s_{\max }^{I}, s_{\max }^{I I}\right\}$.

\subsection{Calculation of Power Flows and Losses of Electricity in Networks with Different} Nominal Voltages

Step 12. Set loads power $\underline{S}_{j}, \forall j \in L_{0}$ and power source voltage $U_{0}$ denotes node $i=0$ voltage;

Step 13. Calculate $c=1, k=0$ and for the $k=0$ iteration take the voltage at the network nodes equal to the nominal:

$$
\underline{U}_{i(0)}=U_{n o m, i}, \quad \forall i \in L \backslash\{0\} .
$$

Step 14. Calculate the number of the next step of the iteration: $k=k+1$. 
Step 15. Formulation of the computing process structure when calculating a network power flow with different nominal voltages:

- Formulation of the calculation structure for the $k=1$ iteration:

$$
\begin{aligned}
& \text { if } k=1 \text {, then } \\
& \left\{x_{\min 1}=0, x_{\max 1}=s_{\max }^{I I},\right. \\
& \left.x_{\min 2}=s_{\max }^{I}, x_{\max 2}=s_{\max }^{I I}\right\} ;
\end{aligned}
$$

- Formulation of the calculation structure for the $k>1$ and the stop condition:

$$
\begin{aligned}
& \text { if } k>1 \text {, then } \\
& \left\{\text { if }\left(\left|U_{j(k-1)}-U_{j(k-2)}\right|>\epsilon, \forall j \in \underset{i \in L_{\left(s_{\max }^{I}+1\right)}}{\bigcup} \Gamma_{i}\right)\right. \text {, then } \\
& \left\{x_{\min 1}=s_{\max }^{I}, x_{\max 1}=s_{\max }^{I I},\right. \\
& x_{\min 2}=s_{\max }^{I}, x_{\max 2}=s_{\max }^{I I}, \\
& \left.\Delta \underline{S}^{(p)}=0, \forall p \in\{1,2, \ldots, 6\}\right\}, \text { otherwise } \\
& \left.\left\{c=0, x_{\min 2}=0, x_{\max 2}=s_{\max }^{I}\right\}\right\},
\end{aligned}
$$

where $x_{\min 1}, x_{\max 1}$ denote, respectively, the lower and upper limits of changing the number of the hierarchy level $s$ at the first stage (from bottom to top); $x_{\min 2}, x_{\max 2}$ denote respectively, the lower and upper limits of the change in $s$ at the second stage (from top to bottom); $c \in\{0,1\}$ denotes the Boolean value to disable $(c=0)$ and enable $(c=1)$ of the computational module "from bottom to top" at the last cycle of the iteration $k$; $\Delta \underline{S}^{(p)}=0, \forall p \in\{1,2, \ldots, 6\}$ denotes total power losses for different types of sections (see Figure 2 and Table 1 ).

First stage. Calculation of flow distribution (module algorithm "from bottom to top").

Step 16. If $c=1$, then go to step 17; otherwise, go to step 21 .

Step 17. Calculate the initial value of the hierarchy level number: $s=x_{\min 1}$.

Step 18. Calculate the number of the next top level in the hierarchy: $s=s+1$.

Step 19. For each Section $(i, j) \in \Gamma_{i}$ and each $i \in L_{s}$, calculate:

- Power losses $\Delta \underline{S}_{i j(k)}$ in resistance $\underline{Z}_{i j}$ of Section $(i, j)$ to calculate the total loss of electricity in the network;

- Power flow $\left(\underline{S}_{i j(k)}\right)^{s Z}$ at the beginning of the resistance $\underline{Z}_{i j}$ in Section $(i, j)$ for voltage $\underline{U}_{j(k)}$ calculation at the end of Section $j$ in the second stage;

- Power flow $\underline{S}_{i j(k)}^{S}$ at the beginning of Section $(i, j)$ to calculate the power flow of the node $i$;

- $\quad$ Power flow $\underline{S}_{i(k)}$ of the node $i$.

The above power flows, depending on the type of sites $(i, j)$, are calculated as follows (see Figure 2 and Table 1): 
- $\quad$ For the sections $(i, j)$ with double-winding transformers with $U_{n o m, i}>35 \mathrm{kV}$ (as can be seen in Figure 2a and Table 1, line 1):

$$
\begin{aligned}
& \text { if }\left(\left(j \notin L_{Y}\right) \wedge\left(U_{n o m, i}>35 \mathrm{kV}\right) \wedge\left(U_{n o m, i}>U_{n o m, j}\right)\right), \\
& \text { then }\left\{\left[\Delta \underline{S}_{i j(k)}, \underline{S}_{i j(k)}^{s Z}, \underline{S}_{i j(k)}^{S}\right]=F_{S}^{(1)}\left[\underline{S}_{j(k)}, \underline{U}_{i(k-1)}, U_{j(k-1)}\right],\right. \\
& \left.\Delta \underline{S}^{(1)}=\Delta \underline{S}^{(1)}+\Delta \underline{S}_{i j(k)}\right\} ;
\end{aligned}
$$

- $\quad$ For the sections $(i, j)$ with overhead power lines with $U_{n o m, i}>35 \mathrm{kV}$ (as can be seen in Figure $2 \mathrm{~b}$ and Table 1 , line 2):

$$
\begin{aligned}
& \text { if }\left(\left(j \notin L_{Y}\right) \wedge\left(U_{n o m, i}>35 \mathrm{kV}\right) \wedge\left(U_{n o m, i}=U_{n o m, j}\right)\right), \\
& \text { then }\left\{\left[\Delta \underline{S}_{i j(k)}, \underline{S}_{i j(k)}^{s Z}, \underline{S}_{i j(k)}^{s}\right]=F_{S}^{(2)}\left[\underline{S}_{j(k)}, U_{i(k-1)}, U_{j(k-1)}\right],\right. \\
& \left.\Delta \underline{S}^{(2)}=\Delta \underline{S}^{(2)}+\Delta \underline{S}_{i j(k)}\right\} ;
\end{aligned}
$$

- $\quad$ For the sections $(i, j)$ with double-winding transformers with $U_{n o m, i} \leq 35 \mathrm{kV}$ (as can be seen in Figure $2 \mathrm{c}$ and Table 1, line 3):

$$
\begin{aligned}
& \text { if }\left(\left(j \notin L_{Y}\right) \wedge\left(U_{n o m, i} \leq 35 \mathrm{kV}\right) \wedge\left(U_{n o m, i}>U_{n o m, j}\right)\right), \\
& \text { then }\left\{\left[\Delta \underline{S}_{i j(k)}, \underline{S}_{i j(k)}^{s Z}, \underline{S}_{i j(k)}^{s}\right]=F_{S}^{(3)}\left[\underline{S}_{j(k)}, U_{j(k-1)}\right],\right. \\
& \left.\Delta \underline{S}^{(3)}=\Delta \underline{S}^{(3)}+\Delta \underline{S}_{i j(k)}\right\} ;
\end{aligned}
$$

- $\quad$ For the sections $(i, j)$ with overhead power lines with $U_{n o m, i} \leq 35 \mathrm{kV}$ (as can be seen in Figure $2 \mathrm{~d}$ and Table 1, line 4):

$$
\begin{aligned}
& \text { if }\left(\left(j \notin L_{Y}\right) \wedge\left(U_{n o m, i} \leq 35 \mathrm{kV}\right) \wedge\left(U_{n o m, i}=U_{n o m, j}\right)\right), \\
& \text { then }\left\{\left[\Delta \underline{S}_{i j(k)}, \underline{S}_{i j(k)}^{s Z}, \underline{S}_{i j(k)}^{s}\right]=F_{S}^{(4)}\left[\underline{S}_{j(k)}, U_{j(k-1)}\right],\right. \\
& \left.\Delta \underline{S}^{(4)}=\Delta \underline{S}^{(4)}+\Delta \underline{S}_{i j(k)}\right\} ;
\end{aligned}
$$

- $\quad$ For the sections $(i, j)$ with primary windings of three-winding transformers with $U_{n o m, i}>35 \mathrm{kV}$ (as can be seen in Figure 2e and Table 1, line 5):

$$
\begin{aligned}
& \text { if }\left(\left(j \in L_{Y}\right) \wedge\left(U_{n o m, i}>35 \mathrm{kV}\right) \wedge\left(U_{n o m, i}=U_{n o m, j}\right)\right), \\
& \text { then }\left\{\left[\Delta \underline{S}_{i j(k)}, \underline{S}_{i j(k)}^{s Z}, \underline{S}_{i j(k)}^{s}\right]=F_{S}^{(5)}\left[\underline{S}_{j(k)}, U_{i(k-1)}, U_{j(k-1)}\right],\right. \\
& \left.\Delta \underline{S}^{(5)}=\Delta \underline{S}^{(5)}+\Delta \underline{S}_{i j(k)}\right\} ;
\end{aligned}
$$

- $\quad$ For the sections $(i, j)$ with secondary windings of three-winding transformers with $U_{n o m, i}>35 \mathrm{kV}$ (as can be seen in Figure 2e and Table 1, line 6):

$$
\begin{aligned}
& \text { if }\left(\left(i \in L_{Y}\right) \wedge\left(U_{n o m, i}>35 \mathrm{kV}\right) \wedge\left(U_{n o m, i}>U_{n o m, j}\right)\right), \\
& \text { then }\left\{\left[\Delta \underline{S}_{i j(k)}, \underline{S}_{i j(k)}^{s Z}, \underline{S}_{i j(k)}^{s}\right]=F_{S}^{(3)}\left[\underline{S}_{j(k)}, U_{j(k-1)}\right],\right. \\
& \left.\Delta \underline{S}^{(6)}=\Delta \underline{S}^{(6)}+\Delta \underline{S}_{i j(k)}\right\} .
\end{aligned}
$$

Using the obtained power flows $\underline{S}_{i j(k)}^{S}, \forall(i, j) \in \Gamma_{i}, \forall i \in L_{S}$, calculate the power flows for each node $i \in L_{S}$ :

$$
\underline{S}_{i(k)}=\sum_{j \in \Gamma_{i}} \underline{S}_{i j(k)}^{S}, \forall i \in L_{s}
$$


Step 20. If $s<x_{\max 1}$, then go to step 18; otherwise, go to step 21 .

Second stage. Calculation of voltages in network nodes (module algorithm "from top to bottom").

Step 21. Calculate the initial hierarchy level number $s=x_{\max 2}$.

Step 22. Calculate voltage $\underline{U}_{j(k)}$ and its module $U_{j(k)}$ for the ending node $j$ of every Section $(i, j) \in \Gamma_{i}$ to calculate the flow distribution at the first stage of the next $k+1$ iteration, and phase $\delta_{j(k)}$ :

- For the sections $(i, j)$ with double-winding transformers or for the sections $(i, j)$ with secondary windings of three-winding transformers:

$$
\begin{aligned}
& \text { if }\left(U_{n o m, i}>U_{n o m, j}\right), \\
& \text { then }\left\{\left[\underline{U}_{j(k)}, U_{j(k)}, \delta_{j(k)}\right]=F_{U}^{(1)}\left[\underline{U}_{i(k)}, U_{i(k)}, \underline{S}_{i j(k)}^{s Z}\right]\right\} ;
\end{aligned}
$$

- For the sections $(i, j)$ with overhead power lines or for the sections $(i, j)$ with primary windings of three-winding transformers:

$$
\begin{aligned}
& \text { if }\left(U_{\text {nom }, i}=U_{n o m, j}\right) \text {, } \\
& \text { then }\left\{\left[\underline{U}_{j(k)}, U_{j(k)}, \delta_{j(k)}\right]=F_{U}^{(2)}\left[\underline{U}_{i(k)}, U_{i(k)}, \underline{S}_{i j(k)}^{s Z}\right]\right\} .
\end{aligned}
$$

Step 23. Calculate the number of the next low level in the hierarchy: $s=s-1$.

Step 24. If $s>0$, then go to step 22; otherwise, go to step 25 .

Step 25. If $c=1$, then go to step 14; otherwise, go to step 26 .

Step 26. Calculate the total losses of power and electricity in the network:

$$
\begin{gathered}
\Delta \underline{S}_{C}=\sum_{p=1}^{6} \Delta \underline{S}^{(p)}=\Delta P_{C}+j \Delta Q_{C} ; \\
\Delta W_{C}=\Delta t \cdot \Delta P_{C}
\end{gathered}
$$

where $\Delta t$ denotes the time interval during which the voltage of the source and the power of the loads are constant, meaning that:

$$
\underline{U}_{0}=\text { const }, \quad \underline{S}_{j}=\text { const }, \quad \forall j \in L_{0} .
$$

The stated approach is focused on applications of radial distribution networks in models. Most usage practices include the calculation and analysis of power supply networks at the design stage and during operation-in addition to modernization. The model's strong points embrace a detailed presentation of network elements following physical processes characteristics; system analysis and accounting for interaction impact; simplicity algorithmization and the automation of existing power supply systems. Disadvantages are associated with the difficulty of applying to complex-closed electrical networks, which reduces the method versatility.

\section{Conclusions}

In this work, a structured hierarchical multilevel approach to the calculation of power flows and losses of electricity in radial electrical networks with different nominal voltages at given loads and voltage of the power source was developed. This approach is based on the representation of the initial network graph in the form of a hierarchical multilevel structure, divided into two stages with nominal voltages $U_{\text {nom }} \leq 35 \mathrm{kV}$ and $U_{n o m}>35 \mathrm{kV}$, and on 
the use of the traditional (manual) engineering two-stage method, where the calculation is performed in a certain sequence, moving along the network structure from bottom to top (stage 1) and from top to bottom (stage 2).

Since the network of the class under consideration consists of different types of sections (power lines with $U_{\text {nom }} \leq 35 \mathrm{kV}$ and $U_{\text {nom }}>35 \mathrm{kV}$, double-winding transformers with $U_{\text {nom }} \leq 35 \mathrm{kV}$ and $U_{\text {nom }}>35 \mathrm{kV}$, primary and secondary windings of three-winding transformers (autotransformers)), then for the organization of the computational process, conditions and predicate functions are established for the choice of equivalent circuits and the corresponding calculation formulas for each type of sections. This also provides for the separation of the computational process for two stages of a hierarchical multilevel structure, for the first stage, a two-stage method with one pass from bottom to top and from top to bottom, and for the second stage, a two-stage iterative method.

The algorithm development as well as the solution of specialized problems highlighted in related works [2,6], involves the further investigation and implementation of software with increased productivity in industrial processes. At the same time, based on this approach, the authors are conducting research to increase the universality of the algorithm's application. Promising results suggest that one could obtain an algorithm based on this one with the possibility of using it in complex-closed networks.

Author Contributions: Conceptualization, S.A., A.G. and D.A.; methodology, S.A. and D.A.; investigation, S.A. and M.S.; writing-original draft preparation, A.T. and E.L.; visualization, D.A.; writing-review and editing, S.S. and I.O.; funding acquisition, A.G. All authors have read and agreed to the published version of the manuscript.

Funding: This work was supported in part by the International Cooperation Project of National Natural Science Foundation of China under Grant 41761144079, in part by the Strategic Priority Research Program of the Chinese Academy of Sciences, in part by the Pan-Third Pole Environment Study for a Green Silk Road under Grant XDA20060303, in part by the K. C. Wong Education Foundation under Grant GJTD-2020-14, in part by the Research Fund for International Scientists of National Natural Science Foundation of China under Grant 42150410393, in part by the CAS PIFI Fellowship under Grant 2021PC0002, in part by the Xinjiang Tianchi Hundred Talents Program under Grant Y848041, in part by the CAS Interdisciplinary Innovation Team under Grant JCTD-2019-20, in part by the project of the Research Center of Ecology and Environment in Central Asia under Grant Y934031, and in part by the Regional Collaborative Innovation Project of Xinjiang Uygur Autonomous Regions under Grant 2020E01010.

Acknowledgments: The authors express their special gratitude to Murat Asanov, in Technical Science, Associate Professor at the Department of Theoretical Foundations of Electrical Engineering and Electrical Engineering, Faculty of Energy, Kyrgyz State Technical University named after I. Razzakov, for their most valuable advice and consultations in the sphere of technical cybernetics.

Conflicts of Interest: The authors declare no conflict of interest.

\section{References}

1. Chen, B.; Xiang, K.; Yang, L.; Su, Q.; Huang, D.; Huang, T. Theoretical Line Loss Calculation of Distribution Network Based on the Integrated Electricity and Line Loss Management System. In Proceedings of the 2018 China International Conference on Electricity Distribution (CICED), Tianjin, China, 17-19 September 2018; pp. 2531-2535. [CrossRef]

2. Asanov, M.; Asanova, S.; Safaraliev, M.; Lyukhanov, E.; Tavlintsev, A.; Shelyug, S. Elementwise power losses calculation in complex distribution power networks represented by hierarchical-multilevel topology structure. Prz. Elektrotechniczny 2021, 11, 106-110. [CrossRef]

3. Ghosh, S.; Sherpa, K.S. An Efficient Method for Load-Flow Solution of Radial Distribution Networks. Int. J. Electr. Comput. Eng. 2008, 2, 2094-2101.

4. Aravindhababu, P.; Ganapathy, S.; Nayar, K. A novel technique for the analysis of radial distribution systems. Int. J. Electr. Power Energy Syst. 2001, 23, 167-171. [CrossRef]

5. Wang, J.; Guo, Z.; Yu, J. Practical calculation method of theoretical line loss in $10 \mathrm{kv}$ power distribution network based on Dscada. In Proceedings of the 2008 China International Conference on Electricity Distribution, Guangzhou, China, 10-13 December 2008; pp. 1-6. [CrossRef] 
6. Asanova, S.; Safaraliev, M.; Askarbek, N.; Semenenko, S.; Aktaev, E.; Kovaleva, A.; Lyukhanov, E.; Staymova, E. Calculation of power losses at given loads and source voltage in radial networks of $35 \mathrm{kV}$ and above by hierarchical-multilevel structured topology representation. Prz. Elektrotechniczny 2021, 1, 15-20. [CrossRef]

7. Moreira Rodrigues, C.E.; de Lima Tostes, M.E.; Holanda Bezerra, U.; Mota Soares, T.; de Matos, E.O.; Serra Soares Filho, L.; dos Santos Silva, E.C.; Ferreira Rendeiro, M.; da Silva Moura, C.J. Technical Loss Calculation in Distribution Grids Using Equivalent Minimum Order Networks and an Iterative Power Factor Correction Procedure. Energies 2021, 14, 646. [CrossRef]

8. Queiroz, L.M.O.; Roselli, M.A.; Cavellucci, C.; Lyra, C. Energy Losses Estimation in Power Distribution Systems. IEEE Trans. Power Syst. 2012, 27, 1879-1887. [CrossRef]

9. Pavičić, I.; Ivanković, I.; Župan, A.; Rubeša, R.; Rekić, M. Advanced Prediction of Technical Losses on Transmission Lines in Real Time. In Proceedings of the 2019 2nd International Colloquium on Smart Grid Metrology (SMAGRIMET), Split, Croatia, 9-12 April 2019; pp. 1-7. [CrossRef]

10. Vempati, N.; Shoults, R.R.; Chen, M.S.; Schwobel, L. Simplified Feeder Modeling for Loadflow Calculations. IEEE Trans. Power Syst. 1987, 2, 168-174. [CrossRef]

11. Pansini, A. Power Transmission and Distribution, 2nd ed.; River Publishers: New York, NY, USA, $2005 ;$ p. 414.

12. Mahmoud, K.; Yorino, N.; Ahmed, A. Optimal Distributed Generation Allocation in Distribution Systems for Loss Minimization. IEEE Trans. Power Syst. 2016, 31, 960-969. [CrossRef]

13. Hung, D.Q.; Mithulananthan, N.; Bansal, R.C. Analytical Expressions for DG Allocation in Primary Distribution Networks. IEEE Trans. Energy Convers. 2010, 25, 814-820. [CrossRef]

14. Acharya, N.; Mahat, P.; Mithulananthan, N. An analytical approach for DG allocation in primary distribution network. Int. J. Electr. Power Energy Syst. 2006, 28, 669-678. [CrossRef]

15. Kansal, S.; Kumar, V.; Tyagi, B. Optimal placement of different type of DG sources in distribution networks. Int. J. Electr. Power Energy Syst. 2013, 53, 752-760. [CrossRef]

16. Murthy, V.; Kumar, A. Comparison of optimal DG allocation methods in radial distribution systems based on sensitivity approaches. Int. J. Electr. Power Energy Syst. 2013, 53, 450-467. [CrossRef]

17. Kalambe, S.; Agnihotri, G. Loss minimization techniques used in distribution network: Bibliographical survey. Renew. Sustain. Energy Rev. 2014, 29, 184-200. [CrossRef]

18. Jain, N.; Singh, S.N.; Srivastava, S.C. A Generalized Approach for DG Planning and Viability Analysis Under Market Scenario. IEEE Trans. Ind. Electron. 2013, 60, 5075-5085. [CrossRef]

19. Vatani, M.; Alkaran, D.S.; Sanjari, M.J.; Gharehpetian, G.B. Multiple distributed generation units allocation in distribution network for loss reduction based on a combination of analytical and genetic algorithm methods. IET Gener. Transm. Distrib. 2016, 10, 66-72. [CrossRef]

20. Begovic, M. Electrical Transmission Systems and Smart Grids, 1st ed.; Springer: New York, NY, USA, $2013 ;$ pp. VI, 326.

21. Shahnia, F.; Arefi, A.; Ledwich, G. Electric Distribution Network Planning, 1st ed.; Springer: Singapore, 2013 ; pp. XVI, 381.

22. Asanova, S.M.; Ahyoev, J.S.; Askarbek, N.; Suerkulov, S.M.; Asanova, D.U.; Safaraliev, M.K. Method for designing drop-of-wire recognition systems on sections of undistorted two-wire power transmission lines. In IOP Conference Series: Materials Science and Engineering; IOP Publishing: Bristol, UK, 2020; Volume 966, p. 012114. [CrossRef] 